\title{
Association of Maternal Observation and Motivation (MOM) Program with M-Health Support on Maternal and Newborn Health
}

\section{Authors:}

1. Premalatha Paulsamy, PhD, King Khalid University, K.S.A

2. Vigneshwaran Easwaran, PhD, King Khalid University, K.S.A

3. Rizwan Ashraf, PhD ,University of Lahore. Pakistan

4. Krishnaraju Venkatesan, $\mathrm{PhD}$, King Khalid University, K.S.A

5. Mervat Moustafa., PhD, King Khalid University, K.S.A

6. Absar Ahmed Qureshi, PhD, King Khalid University, K.S.A

7. Kousalya Prabahar, PhD, University of Tabuk, K.S.A

8. Kalaiselvi Periannan, Oxford University, U.K

9. Rajalakshimi Vasudevan, $\mathrm{PhD}$, King Khalid University, K.S.A

10. Geetha Kandasamy, PhD, King Khalid University, K.S.A

11. Kumarappan Chidambaram, PhD, King Khalid University, K.S.A

12. Ester Mary Pappiya, PhD, Ministry of Health, Najran, K.S.A

13. Kumar Venkatesan, PhD, King Khalid University, K.S.A

14. Vani Manoharan, DNP, Emory University Hospital, Atlanta, GA,USA

\section{Department(s) and institution(s):}

${ }^{1}$ Premalatha Paulsamy, College of Nursing, Mahalah Branch for Girls King Khalid University, Asir Province, Saudi Arabia., Email: pponnuthai@kku.edu.sa, Mobile: +966-563595142. ORCID ID: 0000-0001-5117-480X

${ }^{3}$ Vigneshwaran Easwaran, Department of Clinical Pharmacy, College of Pharmacy, King Khalid University, Abha, Kingdom of Saudi Arabia, Email: vickku.e@ gmail.com, Mobile: +966 50962 4662

${ }^{3}$ Rizwan Ashraf University College of Medicine and Dentistry, The University of Lahore. Pakistan, E Mail:drriz72@yahoo.com , Mobile: +92-333-4061328

${ }^{4}$ Krishnaraju Venkatesan, Department of Pharmacology, College of Pharmacy, King Khalid University, Abha, Asir Province, Saudi Arabia. Email: kvenkatesan@kku.edu.sa. Mobile: +966504839653. ORCID ID: 0000-0003-2853-5907

${ }^{5}$ Mervat Moustafa, College of Nursing, Mahalah Branch for Girls King Khalid University, Asir Province, Saudi Arabia., Email: marb@kku.edu.sa, Mobile: +966-563649168

${ }^{6}$ Absar Ahmed Qureshi, Department of Pharmacology, College of Pharmacy, King Khalid University, Abha, Asir Province, Saudi Arabia. Email: aqureshi@kku.edu.sa, Mobile: +966534539759. ORCID ID: 0000-0002-0577-6700 
${ }^{7}$ Kousalya Prabahar, Assistant Professor, Department of Pharmacy Practice, Faculty of Pharmacy, University of Tabuk,Tabuk - 71491, Kingdom of Saudi Arabia., P.O. Box - 741, Email: kgopal@ut.edu.sa, Mobile: +966- 54201 9537, ORCID ID: 0000-0001-8224-4276

${ }^{8}$ Kalaiselvi Periannan, Lecturer in Mental health Nursing, Oxford School of Nursing \& Midwifery, Faculty of health and life sciences, Oxford, OX3 OFL, Email: kperiannan@brookes.ac.uk, Mobile: + 07838361434

${ }^{9}$ Rajalakshimi Vasudevan, Department of Pharmacology, College of Pharmacy, King Khalid University, Abha, Asir Province, Saudi Arabia. Email: raja@kku.edu.sa, Mobile: +966508426425. ORCID ID: 0000-0002-1173-7724

${ }^{10}$ Geetha Kandasamy, Department of Pharmacology, College of Pharmacy, King Khalid University, Abha, Asir Province, Saudi Arabia. Email: glakshmi@kku.edu.sa, Mobile: +966559208567

${ }^{11}$ Kumarappan Chidambaram, Department of Pharmacology, College of Pharmacy, King Khalid University, Abha, Asir Province, Saudi Arabia. Email: kumarappan @kku.edu.sa. Mobile: +966509291037. ORCID ID:0000-0002-7981-4562

${ }^{12}$ Ester Mary Pappiya,Regional Nursing Administration, Directorate of General Health Affair, Ministry of Health, Najran, Kingdom of Saudi Arabia. Email: easterbala@gmail.com. Mobile: +966-509180584, ORCID ID: 0000-0003-1188- 8845

${ }^{13}$ Kumar Venkatesan, Department of Pharmaceutical Chemistry, College of Pharmacy, King Khalid University, Abha, Asir Province, Saudi Arabia. Email: kumarve@kku.edu.sa. Mobile: +966-505735246. ORCID ID:0000-0001-5077-9380

${ }^{14}$ Vani Manoharan, DNP, RN, Georgia CTSA, Emory University Hospital, Atlanta, GA, Email: vani.manoharan@emoryheslthcare.org, Mobile: 0014045380720

- Corresponding Author 


\begin{abstract}
Maternal and child nutrition has been a critical component of health, sustainable development, and progress in low- and middle-income countries (LMIC). While a decrement in maternal mortality is an important indicator, simply surviving pregnancy and childbirth does not imply better maternal health. One of the fundamental obligations of nations under international human rights law is to enable mothers and teenage girls to endure pregnancy and delivery as an aspect of their enjoyment of reproductive and sexual health and rights and live a dignified life. The aim of this study was to discover the correlation between the Maternal Observation and Motivation (MOM) program and m-Health support for maternal and newborn health. A Comparative study was done among 109 pregnant mothers (study group-94; control group-102 mothers) with not less than 20 weeks of gestation. Maternal outcomes such as $\mathrm{Hb}$, weight gain and newborn results like birth weight and crown- heel length was obtained on the baseline, 28 and 36 weeks of gestation. Other secondary data collected were abortion, stillbirth, low birth weight, major congenital malformations, twin or triplet pregnancies, physical activity and maternal wellbeing. The MOM intervention included initial face to face education, three in-person visits and eight virtual health coaching by WhatsApp. The baseline data on $\mathrm{Hb}$ of the mothers show that $31(32.98 \%)$ vs $27(28.72 \%)$ of the study and control group had anaemia, which improved to $27.66 \%$ and $14.98 \%$ among study group mothers at 28 and 36 weeks of gestation $(p<0.001)$. The weight gain $(p<0.001)$, level of physical activity $(p<0.001)$, and maternal wellbeing $(p<0.01)$ also had significant differences after the Intervention. Even after controlling for potentially confounding variables, the maternal food practices regression model revealed that birth weight was directly correlated with consumption of milk ( $\mathrm{p} 0.001)$, fruits ( $\mathrm{p} 0.01)$, and green vegetables (p 0.05).As per the physical activity and maternal wellbeing regression model, the birth weight and crown heel length were strongly related with the physical activity and maternal wellbeing of mothers at 36 weeks of gestation ( $p<0.05)$. Combining the MOM intervention with standard antenatal care is a safe and effective way to improve maternal welfare while upholding pregnant mothers' human rights.
\end{abstract}

\title{
Keywords:
}

Pregnant Mothers, Physical Activity, Maternal Wellbeing, Antenatal Mothers, Newborn outcomes,M-Health, Low birth weight, Small for gestation, Gestation age, Hemoglobin. 


\section{Background:}

Pregnancy is a once-in-a-lifetime event that can influence maternal health and the health of future generations. Nutrition is vital for maternal and child health, and it is well acknowledged that well-balanced nutrition in early life is the foundation for long-term health ${ }^{1}$. Poor maternal nutrition, along with maternal body composition, metabolism, and placental nutrient supply, are key factors that can influence fetal development and have been associated with a poor pregnancy outcomes and fetal genetic potential expression ${ }^{2}$.

For maternal, fetal, and newborn health, counselling women to promote awareness of the importance of maternal health prior to conception, in pregnancy and advocate a cultural lifestyle modification in favour of a healthy weight is critical. Although a balanced diet is widely available in today's globalised world, a shift to a high-fat, low-quality diet has resulted in inadequate vitamin and mineral intake during pregnancy ${ }^{3}$. When required, micronutrient intakes are difficult to meet through food alone; supplementation and fortification can benefit ${ }^{4}$. The research does not support routine multiple micronutrient supplementation alone $e^{5}$ Still, it emphasises the significance of an individualised approach to identify nutritional deficiencies in individuals, leading to healthy, culturally accepted lifestyle practices prior to conception and in pregnancy, and ultimately to better maternal and newborn outcomes ${ }^{6}$.

According to the World Health Organization (WHO) guidelines on "antenatal care (ANC) for a positive pregnancy experience summery" ${ }^{1}$, counselling on healthy eating and staying physically active during pregnancy is recommended for pregnant women who want to stay healthy and avoid accumulating too much weight. Pregnant women should take a daily iron and folic acid supplement with $30 \mathrm{mg}$ to $60 \mathrm{mg}$ of elemental iron and $400 \mathrm{~g}(0.4 \mathrm{mg})$ of folic acid to avoid maternal anaemia, puerperal sepsis, low birth weight, and premature birth. Each pregnant woman should keep her case notes throughout her pregnancy to ensure continuity, quality of treatment, and a positive pregnancy experience. Antenatal care models with at least eight visits are recommended to reduce perinatal mortality and improve pregnant women's experiences. It is proposed that maternal and newborn health-related behaviours be promoted to a broad range of cadres, including lay health workers, auxiliary nurses, nurses, midwives, and doctors ${ }^{1}$.

"Every mother and newborn receives quality care during the pregnancy, childbirth, and postnatal period," the WHO envisions ${ }^{7}$. There is evidence that effective intervention strategies for preventing or treating all life-threatening maternal complications are affordable ${ }^{8}$. Optimal adaptation and uptake of existing research findings could alleviate nearly two-thirds of the global maternal and newborn disease burden ${ }^{9}$. In 2015, almost 3,03,000 women and adolescent girls died due to pregnancy and delivery complications ${ }^{10}$. The majority of maternal deaths occur in low-resource settings, and most of them can be avoided ${ }^{11}$. Similarly, almost 2.6 million babies were stillborn in 2015 , mostly in low-resource areas ${ }^{12}$.

Nevertheless, the association between maternal nutrition and birth outcome is quite complex and influenced by biological, socioeconomic, and demographic factors. Understanding the relationship between maternal nutrition, pregnancy, and birth outcomes may serve as the basis for nutritional interventions. It will improve birth outcomes and the newborn's long-term health, 
improving quality of life and lowering mortality, morbidity, and healthcare $\operatorname{costs}^{13}$.

Under the international human rights law, one of the fundamental commitments of nations includes enabling women and teenage girls to survive pregnancy and delivery as part of their enjoyment of sexual and reproductive health and rights and living a life of dignity ${ }^{14}$. The human rights-based approach promotes health and wellbeing while preserving dignity and rights, not only avoiding substantial morbidity and mortality.

For this, based on a woman's preferences and available possibilities, we need novel, evidencebased methods of antenatal care to accomplish the "Every Woman Every Child" vision and the Global Strategy for Women's, Children's, and Adolescents' Health. Maternal care also provides an opportunity to interact with and support women, families, and communities at a crucial period in a woman's life.

\section{Significance of the Study}

Maternal nutrition, either malnutrition or overweight, is common and significant in poor perinatal outcomes ${ }^{15}$. Low BMI in early pregnancy augments the risk of both SGA and preterm birth., ${ }^{16}$ A study showed that high BMI increased the risk of preterm birth and Low weight gain also associated with SGA and preterm birth ${ }^{17}$. A well-proven intervention in RCTs improves birth outcomes, especially when given to impoverished women who gain 100 grams (95\% confidence interval: 56-145) at delivery ${ }^{18}$. The WHO has set a global target to reduce LBW by $30 \%$ by 2025 19.

Iron, folate, and vitamin A deficiency are all linked to anaemia. It is estimated that $38.2 \%$ of pregnant women worldwide are affected, with the most significant rates in the WHO areas of South-East Asia (48.7\%) and Africa (48.7\%). (46.3\%) with 0.8 million pregnant women globally having severe anaemia $(<70 \mathrm{~g} / \mathrm{L})$ associated with an increased risk of maternal and infant mortality ${ }^{20}$. Anemia also significantly increases the danger of maternal death by a factor of two. ${ }^{21}$ In 2017, more than 50 million children had BMIs that were too low as a result of inadequate nutrition during pregnancy. About 150 million children worldwide were stunted, limiting children's ability to grow into healthy, active, and productive members of their families, communities, and countries. ${ }^{22}$

In addition to producing anaemia, iron deficiency harms muscular energy usage and, as a result, physical capability and work performance. It also affects immunological state and infection morbidity $^{23}$. Folate (vitamin B9) insufficiency has been related to prenatal neural tube abnormalities in addition to anaemia ${ }^{24}$. Around 19 million pregnant women, especially in Africa and Southeast Asia, suffer from vitamin A insufficiency, which causes night blindness ${ }^{25}$. Iron folic acid supplementation substantially decreased self-reported intrapartum haemorrhage in an Randomized Control Trial in rural Nepal. ${ }^{26}$

Pre-eclampsia has been related to calcium deficiency ${ }^{27}$, and shortages of other vitamins and minerals, such as vitamin E, C, B6, and zinc, have also been suggested to have a role in the 
condition $^{28}$. Zinc insufficiency is linked to weakened immunity ${ }^{29}$. To prevent pre-eclampsia, the WHO recommends daily calcium supplementation at levels of 1.5-2 $\mathrm{g}$ during pregnancy in countries where dietary calcium intake is inadequate ${ }^{30}$.

Early nutrition can influence child development, but it must be combined with early adaptable learning interventions. Due to limited access to comprehensive maternal healthcare, low-income, rural, and other marginalized women are more likely to experience pregnancy- and childbirthrelated complications. ${ }^{31}$

Pregnancy is a time of physical and emotional stress, as well as gradual physiological and psychological changes. Psychological symptoms occur at a higher rate in pregnant women than non-pregnant women and adversely affect pregnancy and postpartum outcomes ${ }^{32}$. It is, therefore, necessary to routinely screen for psychological symptoms during pregnancy and postpartum.

Nutritional insults in fetal life and small birth sizes are common in low-income countries and are associated with severe health consequences ${ }^{33}$. Mobile health, or "mHealth," technologies are increasingly being used to improve chronic disease management and encourage behavior change ${ }^{34}$. Given that more pregnant women are using smartphones, mobile health provides an opportunity to improve pregnancy health behaviors. Hence, this study was undertaken to find the association of Maternal Observation and Motivation (MOM) program with m-Health support on maternal and newborn health.

\section{Objectives:}

To test the hypothesis that nutrition during pregnancy would increase maternal haemoglobin level, birth weight, and maternal wellbeing and assess whether a combination of these interventions would further enhance these outcomes.

\section{Methods:}

\subsection{Design}

A Comparative study was done to assess the effect of the Maternal Observation and Motivation (MOM) program with $\mathrm{m}$-Health support on maternal and newborn health.

\subsection{Participants and Setting:}

The study participants were pregnant women with gestational age not less than 20 weeks with a viable fetus confirmed by ultrasonogram. The study took place in six villages, $30-40 \mathrm{~km}$ from Chennai city and covered 35,000 population. The eligible samples were 196 pregnant women who met the inclusion criteria and were ready to take part in the study.

\subsection{Sample Size and Sampling process:}

The non-probability convenient sampling technique selected 196 samples from six villages near Chennai suburban area. The inclusion criteria included viable fetus, gestational age not less than 20 weeks, no severe illness, written consent for participation and in possession of a smartphone were recruited. The mothers from every three villages were allotted to study (94 mothers) and control group(102 mothers) for convenience and to avoid contamination.

\subsection{Data Collection tools/instruments:}


Section A: The socio-demographic characteristics of the Participants.

Section B: Food Frequency Questionnaire was used to collect the baseline data on diet history.

Section $C$ : Maternal outcomes such as weight $(\mathrm{kg})$ and $\mathrm{Hb}$ at baseline, 28 weeks and 36 weeks were obtained. The Secondary data related to maternal morbidity and mortality such as spontaneous abortion, induced abortion, stillbirth or live birth were obtained from a structured checklist.

Section D: Newborn Outcomes such as Birth weight and Crown Heel length were measured to the nearest $0.1 \mathrm{~cm}$ using Fibreglass tapes (CMS Instruments, London, U.K.). Secondary data like low birth weight, small for gestational age, major congenital malformations, and twin or triplet pregnancies were collected.

Section E: The data was gathered using a pregnancy physical activity (PA) checklist.

Section F: Maternal Wellbeing was assessed by World Health Organization-5 Well-Being Index $(\mathrm{WHO}-5)^{35}$ tool.

\subsection{Assessment}

The participating pregnant women were followed up monthly at home by one of the investigators or research assistants. Information on specified gastrointestinal adverse effects was collected after four weeks of supplementation and the MOM program. If the mother had minor ailments like constipation or heartburns, the home remedies as per WHO guidelines were given. If those symptoms persist or worsens, mothers were referred to the nearby health centres/ hospitals. The weight and haemoglobin level were assessed on venous blood by HemoCue (HemoCue AB) at initial contact, 28- and 36-weeks' gestation. Anaemia was defined as having a hemoglobin level less than $11.0 \mathrm{~g} / \mathrm{ml}$. All participants in both groups were provided with two 3-day food diaries to quantify intakes and physical activity surveys to ascertain self-reported compliance, monitored by the investigating team.

Pregnancy outcomes were classified as spontaneous abortion (unintended loss of a fetus before 28 weeks' gestation as determined by reported last menstrual period), induced abortion (intentional loss of a fetus before 28 weeks' gestation), stillbirth (birth of a dead fetus after 28 weeks' gestation), or live birth (birth of a fetus with any sign of viability). The birth anthropometry was primarily measured by trained nurses within 72 hours of birth. SECA electronic scales (SECA GmbH) were used to measure all birth weights to a precision of $10 \mathrm{~g}$.

The crown heel length of the newborn was measured using standard procedures using domestically manufactured collapsible length boards that were accurate to $1 \mathrm{~mm}$. Training of the interviewers/research assistants on anthropometric measurements was conducted periodically. Weighing equipment was calibrated monthly with standard weights. Interobserver and intraobserver variation studies were conducted every month to ensure the quality of these measurements. The data was gathered using a pregnancy physical activity (PA) checklist.

The duration of each day of physical activity was recorded in the self-monitored diary. The 'Fit" app was downloaded on the mothers' smartphones to observe and motivate their PA to calculate the average weekly minutes spent on physical activity. World Health Organization-5 Well-Being Index (WHO5): The WHO-5 questionnaire (World Health Organization 1998) consists of 5 positively worded items about the respondent's feelings during the preceding 2-week period. 
Pregnancy is a time of physical and emotional stress, as well as progressive physiological and psychological changes.

Psychological symptoms occur at a higher rate in pregnant women than non-pregnant women and adversely affect pregnancy and postpartum outcomes. Therefore, the WHO-5, a short form (5 items) tool was used. The five items are as follows: I have felt cheerful and in good spirits; I have felt calm and relaxed; I have felt active and vigorous; I woke up feeling fresh and rested; My daily life has been filled with things that interest me. Each item is rated on a 6-point Likerttype scale of $0-5$, with 0 indicating the lack of positive feelings during the preceding 2 -weeks and 5 indicating consistent positive feelings. The total raw score, which ranges from 0 to 25 , is multiplied by 4 to obtain the final score, with 0 representing the worst possible well-being and 100 representing the best possible well-being 26 .

\subsection{Intervention}

Women in the control group received standard antenatal care, as well as consistent advice on diet, exercise, and weight gain during pregnancy. The intervention group received routine antenatal care as well as a "Maternal Observation and Motivation (MOM)" Program. The "Maternal Observation and Motivation (MOM)" Program began with a single face-to-face education session conducted to a group of 5-8 antenatal mothers.

This education session was delivered at the first visit and centred and emphasised the importance of nutrition, effect of anaemia, vitamin and mineral deficiency to the mother, foetus and the child in later life, compliance of supplemental medications and nutrition supplement mix, the importance of physical activity and emotional wellbeing of the mother during pregnancy. Participants were encouraged and were informed about a healthy diet, including adding fresh fruits and vegetables, milk and milk products. The recommended diet was approximately equal to the recommended additional calorie, protein and micronutrients.

Under the ICDS programme ${ }^{45}$, the Antenatal (AN) Mother receives supplemental nutrition powder which has the following components in $100 \mathrm{mg}$ : Protein (11 gms), Carbohydrate (55 gms), Calcium (200 mg), Vitamin A (200 mcg), Niacin(4mg), Folic acid (15mcg), Fat (3 mg), Iron (6 mg), Vitamin B1(300mcg), Vitamin B2(350 mcg), Vitamin C (15 mg) and calories (400 kcals). The AN mother receives 165 gms/ day as 15 days ration from Anganwadi centres. In addition to the nutritional mix given by the Government of Tamilnadu, all AN woman with $\mathrm{Hb}$ $=11 \mathrm{gm} / \mathrm{dl}$, were given 100 tablets of Iron $(100 \mathrm{mg})$ and folic acid $(0.5 \mathrm{mg})(1 \mathrm{tablet} /$ day $)$ at 18 week gestation or soon after registered in the study through mother and child protection card (MCP Card), according to the National Nutritional Anaemia Control Program. If the AN woman has the $\mathrm{Hb}$ of $9-10.9 \mathrm{gm} / \mathrm{dl}, 2$ tablets /day for 100 days, and $\mathrm{Hb}$ is 7.1 to $8.9 \mathrm{gm} / \mathrm{dl}$; in addition with two tablets per day, the AN mother was given with iron sucrose injection. Before starting these iron and folic acid supplements, the AN woman was given with Tab. Albendazole $400 \mathrm{mg}$ for anthelmintics treatment. The same protocol was followed in this study too. It was ensured that the control group mothers also followed the same protocol for ethical reasons.

All women in the study group were given 100 tablets of Iron $(60 \mathrm{mg})$ and folic acid $(0.5 \mathrm{mg})$ at 
initial contact according to the National Nutritional Anemia Control Program and the nutritional mix given by the government Tamilnadu. The anaemic mothers were given special consideration and followed the above protocol. The information received at the face-to-face education session was reinforced by smartphone, through WhatsApp messages every 2 weeks (sent by the research team). The research assistants did three follow-up face-to-face in-person home visits besides baseline at 26, 36 weeks of gestation and after delivery. Among four, three research assistants were nurses with master's degrees in Obstetrics and Gynaecology and one with Mental Health Nursing. The research assistants were given training on the assessment of data and counselling of mothers related to MOM and motivating the mothers to comply with the nutrition habits, supplements, regular physical activity and mental wellbeing.

The content of the WhatsApp messages was standardised to a specific theme on a 2-week basis with some discourse between the researchers and participants. Individual attention was given to each mother on her concerns about diet, physiological alterations related to pregnancy and its' management, follow up of nutrition supplementation. Individualised counselling was also given on minor ailments related to pregnancy, and one of the researchers also visited the mothers at least two times during the study period. The virtual meetings were eight times during the study period with three in-person visits. 


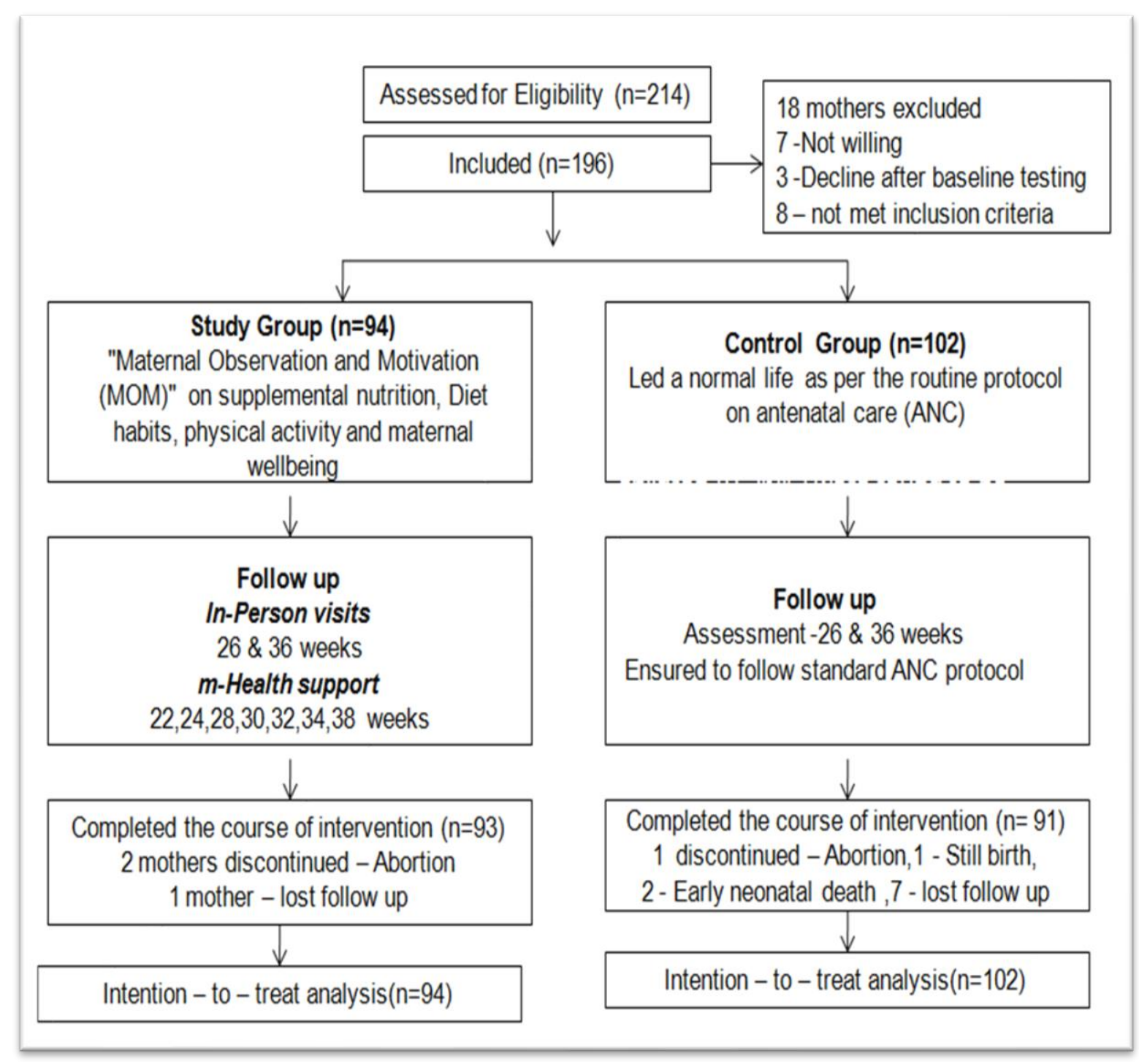

Fig. 1: CONSORT flow diagram of the study

\subsection{Ethical consideration:}

Official permission to conduct the study and ethical approval was obtained from the Institutional Ethical Committee with ICE/LCN/2021-02 dated 29.01.2021. Consent from the participants was collected before starting the study after explaining the aim of the study, their role, the confidentiality of the information and their right to depart from the study at any point of data collection. No harm certificate was obtained from an obstetrician for the MOM program. The control group mothers were also ensured that they were following the standard antenatal care protocol of the state Government. Confidentiality and beneficence were assured hroughout the study period.

\subsection{Statistical analysis:}

The data were processed and analysed by SPSS software using descriptive and inferential statistics. Analysis of data was by intention-to-treat. Analysis of variance was used to examine the main effects of food practices among the two groups on the Hb level of the mothers. A ' $t$ ' test was used to compare differences between group means to compare the MOM intervention with 
the standard program. Multiple regression analysis was used to examine changes in birth weight of the newborn according to maternal food practices, physical activity and maternal wellbeing. In regressions, birth measurements, maternal measurements were analysed as continuous variables. Food practices, physical activity and maternal wellbeing scores were analysed as grouped variables, and $\mathrm{p}<.05$ was considered statistically significant.

\section{Results}

Table 1 shows the baseline data of the mothers of the study and control group. In the study group, 94 mothers and 102 mothers in the control group were enrolled for the study. The mean age of the mothers was $28.1 \pm 4.6$ and $27.9 \pm 4$.8respectively for the study and control group. Regarding the parity, $48.9 \%$ and $53.92 \%$ were primipara mothers in the study and control group. The mean height of the mothers was $144.8 \mathrm{~cm}$ with an SD of 6.1 in the study group, whereas $147 \pm 6.9 \mathrm{~cm}$ was among the control group. The average BMI was $21.7 \pm 3.1$ and $21.3 \pm 2.9$ for the study and control group, respectively. The majority of the mothers had education up to secondary school $(65.96 \%$ vs $55.88 \%)$, and most of them were not working $(77.66 \%$ vs $69.71 \%)$. The education status of the husbands was more or less similar in both groups $(73.4 \%$ vs $76.47 \%)$ and the similar trend was also seen in their occupation status.

The dietary intake of the pregnant mothers was measured using a self-reported checklist on milk and milk products, green leafy vegetables and fruits. This data was used for the regression analysis to determine their relationship with the maternal and newborn outcomes. In addition to this, the mothers were given nutritional supplements as per the government of Tamilnadu.

Table 1: Baseline characteristics of the pregnant women of both study and control group

\begin{tabular}{|c|c|c|}
\hline Variables & Study (n=94) & Control $(n=102)$ \\
\hline Age (in Years) & $28.1 \pm 4.6$ & $27.9 \pm 4.8$ \\
\hline \multicolumn{3}{|l|}{ Parity } \\
\hline Primi mothers & $46(48.9 \%)$ & $55(53.92 \%)$ \\
\hline Multi para mothers & $48(51.1 \%)$ & $47(46.08 \%)$ \\
\hline Height (cm) & $144.8 \pm 6.1$ & $147 \pm 6.9$ \\
\hline Weight (kg) & $45.8 \pm 4.3$ & $46.1 \pm 3.9$ \\
\hline BMI (kg/m2) & $21.7 \pm 3.1$ & $21.3 \pm 2.9$ \\
\hline \multicolumn{3}{|l|}{ Educational Attainment } \\
\hline Primary or less & $21(19.74 \%)$ & $19(18.63 \%)$ \\
\hline Up to Secondary & $62(65.96 \%)$ & $57(55.88 \%)$ \\
\hline Completed college education & $11(11.70 \%)$ & $26(25.49 \%)$ \\
\hline \multicolumn{3}{|l|}{ Occupation } \\
\hline Semiskilled/unskilled & $16(17.02 \%)$ & $19(18.63 \%)$ \\
\hline Skilled/self-employed & $3(3.19 \%)$ & $5(4.9 \%)$ \\
\hline Professional & $2(2.13 \%)$ & $7(6.7 \%)$ \\
\hline Not working & $73(77.66 \%)$ & $71(69.71 \%)$ \\
\hline \multicolumn{3}{|l|}{ Husband's Education } \\
\hline Primary or less & $17(18.7 \%)$ & $16(15.69 \%)$ \\
\hline
\end{tabular}




\begin{tabular}{|l|c|c|} 
Secondary & $69(73.4 \%)$ & $78(76.47 \%)$ \\
\hline Graduate & $8(8.5 \%)$ & $8(7.84 \%)$ \\
\hline Husband's Occupation & $58(61.7 \%)$ & $62(60.8 \%)$ \\
\hline Semi-skilled/unskilled & $24(25.53 \%)$ & $27(26.46 \%)$ \\
\hline Skilled/self-employed & $4(4.26 \%)$ & $6(5.9 \%)$ \\
\hline Professional & $8(8.51 \%)$ & $7(6.84 \%)$ \\
\hline Not working/other & \multicolumn{2}{|l|}{} \\
\hline Dietary intake & $43(45.74 \%)$ & $50(49.02 \%)$ \\
\hline Milk and milk products (other than in coffee/tea) & $31(33 \%)$ & $37(36.27 \%)$ \\
\hline 1 time/wk & $20(21.28 \%)$ & $15(14.71 \%)$ \\
\hline $1-6$ times/wk & & \\
\hline$\geq 7$ times/wk & $23(24.47 \%)$ & $27(26.47 \%)$ \\
\hline Green Leafy Vegetables & $61(64.89 \%)$ & $58(56.86 \%)$ \\
\hline 1 time/wk & $10(10.6 \%)$ & $17(16.67 \%)$ \\
\hline $1-6$ times/wk ) & & \\
\hline$\geq 7$ times/wk & $14(14.89 \%)$ & $19(18.63 \%)$ \\
\hline Fruits & $59(55.46 \%)$ & $62(60.78 \%)$ \\
\hline 1 time/wk & $21(22.34 \%)$ & $21(20.59 \%)$ \\
\hline $1-6$ times/wk &
\end{tabular}

Table 2: Comparison of $\mathrm{Hb}$ Status among Study and Control Group Mothers at different periods of observation

\begin{tabular}{|c|c|c|c|}
\hline $\begin{array}{c}\text { Maternal Hemoglobin } \\
\text { Level }\end{array}$ & $\begin{array}{c}\text { Study Group Mean } \\
\text { (SD) }\end{array}$ & $\begin{array}{c}\text { Control Group } \\
\text { Mean (SD) }\end{array}$ & $\begin{array}{l}\text { t value } \\
\text { p-value }\end{array}$ \\
\hline $\begin{array}{c}\text { Haemoglobin level at } \\
\text { baseline, } g / L\end{array}$ & $\begin{array}{l}110.4 \\
(3.08)\end{array}$ & $\begin{array}{l}110.1 \\
(2.91)\end{array}$ & $\begin{array}{c}\mathrm{t}=0.848 \\
\mathrm{p}=0.397(\mathrm{~N} . \mathrm{S})\end{array}$ \\
\hline $\begin{array}{c}\text { Haemoglobin level at } 28 \\
\text { wkgestation, } g / L\end{array}$ & $\begin{array}{l}112.7 \\
(4.13)\end{array}$ & $\begin{array}{l}112.1 \\
(3.99)\end{array}$ & $\begin{array}{c}\mathrm{t}=0.199 \\
\mathrm{p}=0.843 \text { (N.S) }\end{array}$ \\
\hline $\begin{array}{c}\text { Haemoglobin level at } 36 \\
\text { wk gestation, g/L }\end{array}$ & $\begin{array}{l}113.1 \\
(3.16)\end{array}$ & $\begin{array}{l}112.5 \\
(3.05)\end{array}$ & $\begin{array}{c}\mathrm{t}=0.985 \\
\mathrm{p}=0.21(\mathrm{~N} . \mathrm{S})\end{array}$ \\
\hline Repeated ANOVA & $\mathrm{F}=19.305, \mathrm{P}=0.000^{*}$ & $\mathrm{~F}=0.633, \mathrm{P}=0.532$ & \\
\hline
\end{tabular}

Table 2 shows the comparison of Hb Status among Study and Control Group Mothers at different periods of observation. For the Study group, the mean Hb was 110.4 with an SD of 3.08 at baseline, 112.7 with an SD of 4.13 and 113.1 with SD of 3.16 at 28 and 36 weeks of gestation. The study group showed a significant difference between the study periods at $p=0.000$ as per repeated ANOVA. 
Table 3: The Maternal and newborn outcomes among pregnant mothers

\begin{tabular}{|c|c|c|c|}
\hline Maternal Outcome Variables & Study Group (n=94) & $\begin{array}{c}\text { Control Group } \\
(\mathbf{n = 1 0 2})\end{array}$ & P \\
\hline Anaemia $(\mathbf{H b}<\mathbf{1 1 0 g} / \mathbf{L})$ & & & \\
\hline At 28 Weeks & $26(27.66 \%)$ & $31(30.39 \%)$ & 0.001 \\
\hline At 36 Weeks & $14(14.98 \%)$ & $19(18.63 \%)$ & \\
\hline Weight Gain & & & \\
\hline At 28 Weeks & $43.9 \pm 6.2$ & $41.8 \pm 8.1$ & \\
\hline At 36 Weeks & $47.6 \pm 7.4$ & $46.2 \pm 6.7$ & 0.001 \\
\hline Physical activity (mts/wk) & & & \\
\hline Pre-Intervention & $81 \pm 11$ & $86 \pm 16$ & 0.001 \\
\hline Post-Intervention & $131 \pm 29$ & $103 \pm 17$ & \\
\hline Maternal Wellbeing & & & 0.01 \\
\hline Pre-Intervention & $54 \pm 13$ & $59 \pm 18$ & \\
\hline Post-Intervention & $81 \pm 19$ & $67 \pm 11$ & 0.01 \\
\hline Newborn Outcome Variables & & & 0.001 \\
\hline Birth Weight & $2.780 \pm 0.560$ & $2.560 \pm 0.490$ & 0.01 \\
\hline Crown Heal Length & $47.6 \pm 3.0$ & $46.8 \pm 3.5$ & \\
\hline Gestational Age at Birth & $38.9(38.6-39.1)$ & $38.6(38.4-39.0)$ & \\
\hline The baseline data on Hb & $31(32.98 \%)$ & \\
\hline
\end{tabular}

The baseline data on $\mathrm{Hb}$ show that $31(32.98 \%)$ vs $27(28.72 \%)$ of the study and control group had anaemia, which was improved to $27.66 \%$ and $14.98 \%$ among study group mothers at 28 and 36 weeks of gestation. There was a significant dissimilarity in anaemia status among the study and control group at $\mathrm{p}<0.001$ after Intervention. The weight gain among the intervention group mothers also showed a significant disparity at $\mathrm{p}<0.001$ level. There was a significant variation between physical activity and maternal wellbeing groups at $p<0.001$ and $p<0.01$ level (Table 3).

The newborn outcomes show a significant difference at $\mathrm{p}<0.001$ in crown heel length and birth weight and gestational age at birth at $p<0.01$. The mean birth weight of the study group was slightly higher than the control group $(2.780 \pm 0.560$ vs $2.560 \pm 0.490)$. Similarly, the crown heal length was $47.6 \pm 3.0$ vs $46.8 \pm 3.5$ among the study and control group, respectively. 
Table 5: Multiple regression analysis of the relationship of the maternal food practices in 36 weeks of gestation with newborn's birth weight

\begin{tabular}{|c|c|c|c|c|c|c|c|c|c|c|}
\hline \multirow{2}{*}{$\begin{array}{c}\text { Dependent } \\
\text { Variable }\end{array}$} & \multirow{2}{*}{$\begin{array}{l}\text { Independent } \\
\text { Variables }\end{array}$} & \multicolumn{3}{|c|}{ Milk product intake } & \multicolumn{3}{|c|}{$\begin{array}{c}\text { Green Leafy } \\
\text { Vegetables intake }\end{array}$} & \multicolumn{3}{|c|}{ Fruits intake } \\
\hline & & $\mathbf{R}^{2}$ & $\boldsymbol{\beta}$ & $\mathbf{P}$ & $\mathbf{R}^{2}$ & $\boldsymbol{\beta}$ & $\mathbf{P}$ & $\mathbf{R}^{2}$ & $\boldsymbol{\beta}$ & $\mathbf{P}$ \\
\hline \multirow[b]{2}{*}{$\begin{array}{l}\text { Birth } \\
\text { weight of } \\
\text { new-born } \\
\text { (g) }\end{array}$} & $\begin{array}{l}\text { Sex, Parity, } \\
\text { Gestational } \\
\text { week at birth }\end{array}$ & $\begin{array}{l}19.8 \\
(0.87)\end{array}$ & 16.9 & $<0.001 *$ & $\begin{array}{l}23.1 \\
(1.63)\end{array}$ & 6.7 & $<0.05^{*}$ & $\begin{array}{l}22.1 \\
(0.98)\end{array}$ & 5.8 & $<0.01 *$ \\
\hline & $\begin{array}{l}\text { Sex, Parity, } \\
\text { Gestational } \\
\text { week at birth } \\
\text { and baseline } \\
\text { weight of } \\
\text { Mother }\end{array}$ & $\begin{array}{l}29.3 \\
(1.8)\end{array}$ & 17.5 & $<0.001 *$ & $\begin{array}{l}23.4 \\
(0.47)\end{array}$ & 5.1 & $<0.05^{*}$ & $\begin{array}{l}31.6 \\
(0.83)\end{array}$ & 9.1 & $<0.05^{*}$ \\
\hline
\end{tabular}

The birth weight was strongly related with the consumption of milk at 36 weeks of gestation $(p<0.001)$, fruits $(p<0.01)$ and with green vegetables (GLV) $(p<0.05)$ even after adjustment for potentially confounding variables such as sex, parity, gestational age at birth and baseline weight of mothers (Table 5).

Table 6: Relationship between physical activity and maternal wellbeing at 36 weeks of gestation with newborn outcomes

\begin{tabular}{|c|c|c|c|}
\hline $\begin{array}{l}\text { Dependent } \\
\text { Variable }\end{array}$ & Independent Variable & Physical Activity & Maternal Wellbeing \\
\hline \multirow{2}{*}{$\begin{array}{l}\text { Birth } \\
\text { Weight }\end{array}$} & $\begin{array}{l}P 1 \text { (Sex, Parity and baseline weight of } \\
\text { mother) }\end{array}$ & $<0.05$ & $<0.05$ \\
\hline & $\begin{array}{l}P 1 \text { and Intake of Milk products, GLV } \\
\text { and Fruits }\end{array}$ & $<0.001$ & $<0.05$ \\
\hline \multirow{2}{*}{$\begin{array}{l}\text { Crown } \\
\text { Heal } \\
\text { Length }\end{array}$} & $\begin{array}{l}P 1(\text { Sex, Parity and baseline weight of } \\
\text { mother) }\end{array}$ & $<0.01$ & $<0.05$ \\
\hline & $\begin{array}{l}P 1 \text { and Intake of Milk products, GLV } \\
\text { and Fruits }\end{array}$ & $<0.05$ & $<0.05$ \\
\hline
\end{tabular}

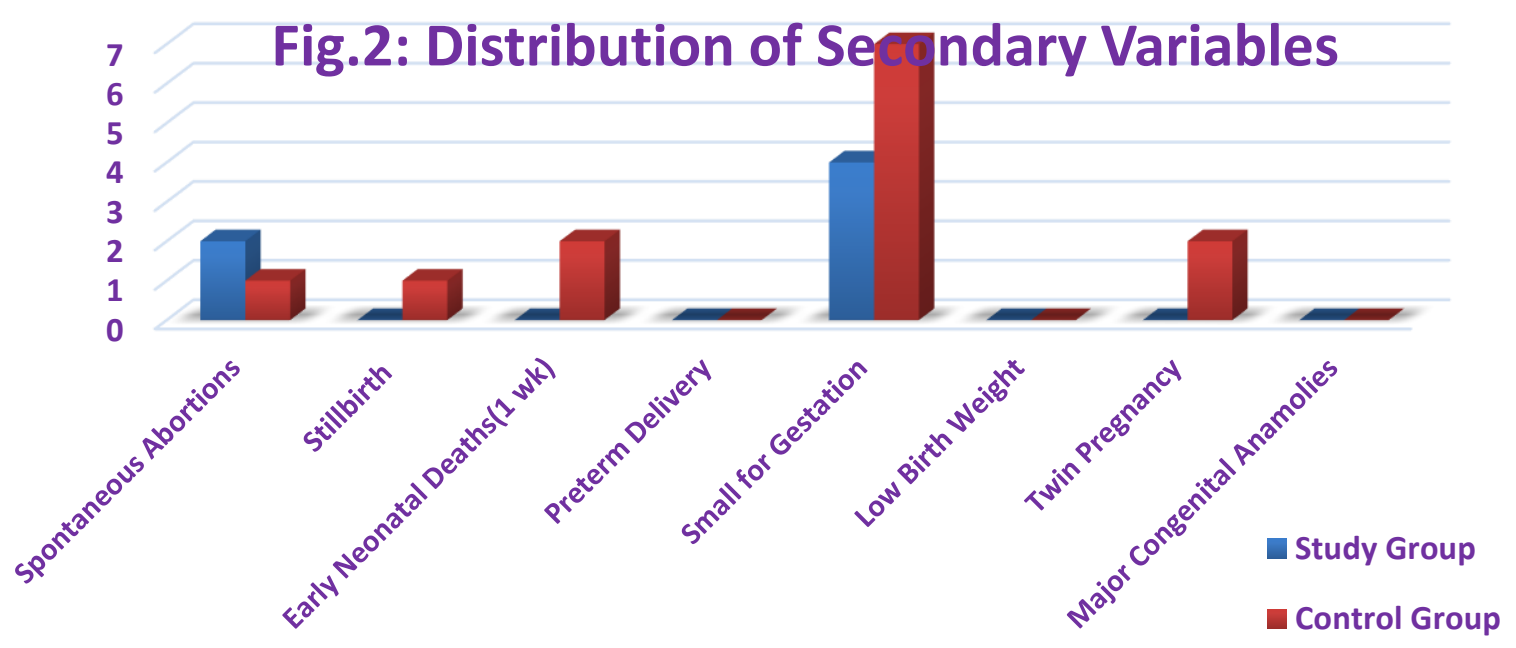


The newborn's birth weight and crown heel length were strongly connected with the physical activity at 36 weeks of gestation $(\mathrm{p}<0.001)$ after adjusting the predictor variables such as Sex, Parity and baseline weight of the mother, Intake of Milk products, GLV and Fruits. Maternal wellbeing also was shown a significant influence on the birth weight and crown heel length of the newborn $(\mathrm{p}<0.05)$ (Table 6).

\section{Discussion}

This study was done to compare the effect of the Maternal Observation and Motivation (MOM) program on maternal outcomes such as weight $(\mathrm{kg})$ plus $\mathrm{Hb}$ at baseline, 28 and 36 weeks, and newborn outcomes like birth weight, crown-heel length and gestational age at birth. The secondary data such as preterm birth (PTM), spontaneous abortion, stillbirth, low birth weight, small for gestational age, major congenital malformations, and twin or triplet pregnancies were obtained from a structured checklist. The strengths of our study were that it was communitybased. The mothers were continuously observed and motivated by the qualified nurses for the compliance of the intervention as well as to promote their wellbeing, throughout their pregnancy. Also, according to the WHO recommendations that pregnant women be followed up for at least 8 times during their pregnancy, in this project, the mothers had four face-to-face counselling sessions and eight virtual follow-ups with the health care professionals through smartphones.

The baseline data on $\mathrm{Hb}$ of the mothers show that around $29 \%$ of them had anaemia, which was improved to $27.66 \%$ and $14.98 \%$ among study group mothers at 28 and 36 weeks of gestation after the Intervention. According to the findings of a study, globally, in 2016, an estimated 35.3 million pregnant women worldwide or $40 \%$, were anaemic. Among them, $19 \%$ of women are affected by iron deficiency. ${ }^{36}$ The WHO also says that anaemia among pregnant women ranges from $14 \%$ in affluent countries to $65 \%-75 \%$ in India. ${ }^{37}$ Even though anaemia is an easily curable and avoid illness, it is strongly linked to pregnancy. By increasing each $1 \mathrm{~g} / \mathrm{dL}$ of mean haemoglobin $(\mathrm{Hb})$ in late pregnancy reduces the odds of maternal deaths by $29 \%{ }^{38}$. Reduced intake, excess demand in multigravida women, altered metabolism, low socioeconomic status, illiteracy, early marriage, and infectious diseases such as hookworm infestations may be the causal factors linked to the occurrence of anaemia during pregnancy ${ }^{39}$. Hence, the improved $\mathrm{Hb}$ among mothers of this study, enhanced the pregnancy related outcomes and nutrition education and counseling during pregnancy is apromising strategy to improve maternal and newborn health.

In addition, inadequate folate levels in the blood before conception and in the first trimester can cause severe fatal neural tube abnormalities. Spina bifida and anencephaly, the two most prevalent kinds of neural tube disorders, affect an estimated 300,000 babies each year ${ }^{37,40}$. Therefore, it is crucial to improve pregnant mothers' haemoglobin and folic acid level to elevate the health status of the foetus and future generations.

According to a few prospective studies on maternal nutrition, after controlling for a variety of covariates, the maternal thinness, as defined by a low mid-upper arm circumference, was linked to all-cause maternal death (up to 42 days postpartum) in $\mathrm{Nepal}^{26}$ as well as severe haemorrhage 
and sepsis morbidity in Bangladesh ${ }^{41}$. The study on 'improving women's diet quality preconceptionally and during gestation: effects on birth weight and prevalence of low birth weight found that there was a significant disparity in anaemia status and weight gain among the study and control groups at $\mathrm{p}<0.001$ after the intervention which denied the effect of daily snack with leafy vegetables, fruit, and milk before conception and during pregnancy on the birth weight ${ }^{42}$. Hence, the tailor made health coach approach of this present study, with the additional emphasis on physical activity and mothers' mental health proved to be effective.

As per the concept, the WHO's shift of considering diet quality and promoting healthy eating practices on antenatal care recommends counselling on healthy eating and keeping physically active during pregnancy ${ }^{43}$. Also, under the International human rights law, one of the fundamental commitments of nations include enabling women and teenage girls to survive pregnancy and delivery, as part of their enjoyment of sexual and reproductive health rights, as well as living a life of dignity ${ }^{14}$. Hence, by considering the above facts and providing a nutritious diet, pregnant women need additional support in the form of emotional and social motivation and individualised care during pregnancy.

This study's strong point was that it adopted an individualised approach for pregnant women with in-person interactions and the most novel approach of m-Health support through smartphones. This allowed the investigators to meet the mothers often and give custom-made interactions and resolutions for the women. This was reflected in the study findings on physical activity, maternal wellbeing and the outcome variables of the study. There was a significant dissimilarity between physical activity and maternal wellbeing among groups in the present study at $p<0.001$ and $\mathrm{p}<0.01$ levels.

Nearly three million annual newborn deaths account for an estimated $44 \%$ of all under-five deaths globally. There is solid evidence for various therapies on prevention of this, provided alone or in packages, across both time and place continuums (preconception, pregnancy, birth, and postnatal). While these interventions can prevent $70 \%$ of newborn fatalities (and more than one-third of stillbirths), ${ }^{44}$ the most challenging issues ahead are overcoming bottlenecks and healthcare system barriers to achieve high coverage and quality at scale. In the present study, with the MOM intervention, the newborn outcomes show significant differences at $p<0.001$ in crown heel length, birth weight and gestational age at birth at $\mathrm{p}<0.01$, respectively. The mean birth weight of the study group was slightly higher than the control group $(2.780 \pm 0.560 \mathrm{vs}$ $2.560 \pm 0.490$ ). Similarly, the crown heal length was $47.6 \pm 3.0$ vs $46.8 \pm 3.5$ among the study and control groups. As the present study had taken up the individual attention on the antenatal mothers and included regular monitoring and motivation to improve the mothers' physical and mental wellbeing of the mothers, this could have been possible.

According to the maternal food practices regression model, the birth weight was strongly associated with the consumption of milk at 36 weeks of gestation $(p<0.001)$, fruits $(p<0.01)$ and green vegetables $(\mathrm{p}<0.05)$ even after adjustment for potentially confounding variables such as gender, parity, gestational age at birth and baseline weight (Table 5). This gives the insight that consuming the supplements alone will not be enough to improve the birth weight. Consumption 
of milk and milk products, fresh fruits, vegetables and green leafy vegetables play a significant role other than nutrition supplementation with the foetal growth and birth weight.

As per the physical activity and maternal wellbeing regression model, the birth weight and crown heel length were strongly related with the physical activity and maternal wellbeing of mothers at 36 weeks of gestation $(p<0.05)$ even after adjustment for potentially confounding variables such as gender, parity, gestational age at birth, baseline, intake of milk products, GLV and Fruits. This finding suggests that the newborn outcome variables such as birth weight and crown heel length were strongly linked with the mothers' physical activity and maternal wellbeing of the mothers. Hence, this multi-component MOM intervention incorporating diet, nutritional supplements, physical activity and maternal wellbeing by face-to-face interaction with continuous observation and motivation through m-Health improved the maternal and newborn outcomes significantly. However, among the independent variables, physical activity and maternal wellbeing played a significant role in the improvement of newborn outcomes in addition to dietary habits, including milk products, GLV and fruits.

Our results contrast with the trails conducted by two prospective studies ${ }^{37,42}$ that meagre nutrition supplementation and dietary modification were unsuccessful in bringing the desired changes in the newborn outcome variables like birth weight, length, and gestational age birth. Since optimal maternal weight and $\mathrm{Hb}$ are the essential components of maternal and newborn care, improving these outcomes by modifying dietary habits and improving physical activity and maternal wellbeing by continuous monitoring and motivation is reasonable for any intervention trials. Interventions including incessant motivation may enhance the compliance of nutrition supplements, dietary modification, and adherence to expected physical activity and improve maternal wellbeing, which might have improved the outcomes.

\section{Conclusion}

While reducing maternal mortality is an important indicator, simply surviving pregnancy and childbirth does not imply improved maternal health. The burden of maternal morbidity can have long-term consequences for women's health and wellbeing. Adopting a human rights framework for universal health necessitates the provision of high-quality care not only during pregnancy and labour and before and after childbirth. It is critical to broadening the focus on mortality to include morbidity to achieve health for all. This MOM intervention involving face to face counselling, constant motivation and observation by $\mathrm{m}$-Health have improved compliance, physical activity behaviour and maternal wellbeing and eventually improved maternal and newborn health. Hence, it is a safe and effective measure to use MOM intervention with standard antenatal care to improve maternal wellbeing from the human rights point of view and reduce the disease burden. 


\section{Funding}

This research was funded by the Deanship of Scientific Research at King Khalid University; Grant number "RGP 2/186/42".

\section{Institutional Review Board Statement}

Institution Ethical Committee gave an ethical clearance with IEC/LCN/2021-2 dated 29.01.2021.

\section{Informed Consent Statement}

Written informed consent was obtained from the participants of the study to publish this paper.

\section{Data Availability Statement}

The data presented in this study is available on request from the corresponding author.

\section{Declaration of Conflicting Interests}

The authors declare no conflict of interest.

\section{Author Contributions}

All authors have read and agreed to the published version of the manuscript.

\begin{tabular}{|l|l|}
\hline $\begin{array}{l}\text { Premalatha } \\
\text { Paulsamy }\end{array}$ & $\begin{array}{l}\text { Conceptualisation, Formal analysis, Investigation, Methodology, } \\
\text { Project administration, Resources, Software, Supervision, Validation, } \\
\text { Visualization, Writing - original draft, Writing - review \& editing }\end{array}$ \\
\hline $\begin{array}{l}\text { Vigneshwaran } \\
\text { Easwaran }\end{array}$ & $\begin{array}{l}\text { Data curation, Formal analysis, Methodology, Project administration, } \\
\text { Resources, Validation, Writing - review \& editing }\end{array}$ \\
\hline Rizwan Ashraf & $\begin{array}{l}\text { Conceptualisation, Methodology, Project administration, Writing - } \\
\text { original draft, Writing - review \& editing }\end{array}$ \\
\hline $\begin{array}{l}\text { Krishnaraju } \\
\text { Venkatesan }\end{array}$ & $\begin{array}{l}\text { Conceptualisation, Formal analysis, Funding acquisition, } \\
\text { Methodology, Project administration, Resources, Software, } \\
\text { Supervision, Validation, Visualization, Writing - original draft, } \\
\text { Writing - review \& editing. }\end{array}$ \\
\hline
\end{tabular}




\begin{tabular}{|c|c|}
\hline Mervat Moustafa & $\begin{array}{l}\text { Conceptualisation, Data curation, Methodology, Project } \\
\text { administration, Validation, Writing - original draft, Writing - review } \\
\text { \& editing }\end{array}$ \\
\hline $\begin{array}{l}\text { Absar Ahmed } \\
\text { Qureshi }\end{array}$ & $\begin{array}{l}\text { Data curation, Formal analysis, Methodology, Project administration, } \\
\text { Validation, Visualisation, Writing - review \& editing. }\end{array}$ \\
\hline Kousalya Prabahar & $\begin{array}{l}\text { Formal analysis, Methodology, Project administration, Software, } \\
\text { Supervision, Validation, Visualization, Writing - original draft, } \\
\text { Writing - review \& editing. }\end{array}$ \\
\hline Kalaiselvi Periannan & $\begin{array}{l}\text { Data curation, Formal analysis, Methodology, Project administration, } \\
\text { Resources, Validation, Writing - review \& editing }\end{array}$ \\
\hline $\begin{array}{l}\text { Rajalakshimi } \\
\text { Vasudevan }\end{array}$ & $\begin{array}{l}\text { Conceptualisation, Investigation, Methodology, Project } \\
\text { administration, Resources, Software, Supervision, Validation, } \\
\text { Visualization, Writing - review \& editing }\end{array}$ \\
\hline Geetha Kandasamy & $\begin{array}{l}\text { Data curation, Formal analysis,Methodology, Project administration, } \\
\text { Validation, Writing - original draft, Writing - review \& editing }\end{array}$ \\
\hline $\begin{array}{l}\text { Kumarappan } \\
\text { Chidambaram }\end{array}$ & $\begin{array}{l}\text { Conceptualisation, investigation, Methodology, Project } \\
\text { administration, Supervision, Writing - review \& editing }\end{array}$ \\
\hline Ester Mary Pappiya & $\begin{array}{l}\text { Conceptualisation, investigation, Methodology, Project } \\
\text { administration, Supervision, Writing - review \& editing }\end{array}$ \\
\hline Kumar Venkatesan & $\begin{array}{l}\text { Formal analysis, Methodology, Project administration, Resources, } \\
\text { Software, Validation, Writing - review \& editing }\end{array}$ \\
\hline Vani Manoharan & $\begin{array}{l}\text { Conceptualisation, Investigation, Data curation, Project } \\
\text { administration, Resources, Supervision, Validation, Visualization, } \\
\text { Writing - review \& editing }\end{array}$ \\
\hline
\end{tabular}

\section{Acknowledgements}

The authors extend their sincere appreciation to the Deanship of Scientific Research at King Khalid University for funding this study through the Large Research Group Project under grant number "RGP 2/186/42". Also, we extend the gratitude to the mothers and their families of both the study and control group and the research assistants. 


\section{Referenes}

1. WHO recommendations on antenatal care for a positive pregnancy experience https://www.who.int/publications/i/item/9789241549912 accessed 27 Oct. 2021 27.10.2021

2. 2.Janna L. Morrison and Timothy R. H. Regnault. Nutrition in Pregnancy: Optimising Maternal Diet and Fetal Adaptations to Altered Nutrient Supply. Nutrients, 2016: 8, 342; doi:10.3390/nu8060342

3. Preconception care: Maximizing the gains for maternal and child health https://www.who.int/maternal_child_adolescent/documents/preconception_care_policy_bri ef.pdf accessed 27 Oct. 2021 27.10.2021

4. Tam E, Keats EC, Rind F, Das JK, Bhutta AZA. Micronutrient Supplementation and Fortification Interventions on Health and Development Outcomes among Children UnderFive in Low- and Middle-Income Countries: A Systematic Review and Meta-Analysis. Nutrients. 2020 Jan 21;12(2):289. doi: 10.3390/nu12020289. PMID: 31973225; PMCID: PMC7071447.

5. Misner B. Food alone may not provide sufficient micronutrients for preventing deficiency. J Int Soc Sports Nutr. 2006;3(1):51-55. doi:10.1186/1550-2783-3-1-51

6. Stephenson J, Heslehurst N, Hall J, Schoenaker DAJM, Hutchinson J, Cade JE, Poston L, Barrett G, Crozier SR, Barker M, Kumaran K, Yajnik CS, Baird J, Mishra GD. Before the beginning: nutrition and lifestyle in the preconception period and its importance for future health. Lancet. 2018 May 5;391(10132):1830-1841. doi: 10.1016/S0140-6736(18)30311-8.

7. Tunçalp Ö, Were WM, MacLennan C, Oladapo OT, Gülmezoglu AM, Bahl R et al. Quality of care for pregnant women and newborns-the WHO vision. BJOG. 2015;122(8):1045-9. doi:10.1111/1471-0528.13451.

8. Campbell OMR, Graham WJ; The Lancet Maternal Survival Series Steering Group. Strategies for reducing maternal mortality: getting on with what works. Lancet. 2006;368:1284-99.

9. Fisk NM, McKee M, Atun, R. Relative and absolute addressability of global disease burden in maternal and perinatal health by investment in R\&D. Trop Med Int Health. 2011;16(6):662-8.

10. Alkema L, Chou D, Hogan D, Zhang S, Moller A-B, Gemmill A et al.; United Nations Maternal Mortality Estimation Inter-Agency Group collaborators and technical advisory group. Global, regional, and national levels and trends in maternal mortality between 1990 
and 2015, with scenario-based projections to 2030: a systematic analysis by the UN Maternal Mortality Estimation Inter-Agency Group. Lancet. 2016;387(10017):462-74. doi:10.1016/ S0140-6736(15)00838-7.

11. Maternal mortality. Fact sheet No. 348; Geneva: World Health Organization; 2014 (http://www. who.int/mediacentre/factsheets/fs348/en/index.html, accessed 22 Oct. 2021).

12. Blencowe H, Cousens S, Bianchi Jassir F, Chou D, Mathers C et al. National, regional, and worldwide estimates of stillbirth rates in 2015, with trends from 2000: a systematic analysis. Lancet. 2016;4(2):e98-108. doi:10.1016/S2214- 109X(15)00275-2.

13. Imdad A, Bhutta ZA. Maternal nutrition and birth outcomes: effect of balanced proteinenergy supplementation. Paediatr Perinat Epidemiol. 2012 Jul;26 Suppl 1:178-90. doi: 10.1111/j.1365-3016.2012.01308.x. PMID: 22742610.

14. Office of the United Nations High Commissioner for Human Rights (OHCHR). Technical guidance on the application of a human rights-based approach to the implementation of policies and programmes to reduce preventable maternal morbidity and mortality. Human Rights Council, twentieth session. New York (NY): United Nations General Assembly; 2012 (A/ HRC/21/22; http://www2.ohchr.org/english/issues/women/docs/A.HRC.21.22_en.pdf,

15. 16. Tang AM, Chung M, Dong K, Terrin N, Edmonds A, Assefa N et al. Determining a global mid upper arm circumference cut off to assess malnutrition in pregnant women. Washington (DC): FHI 360/Food and Nutrition Technical Assistance III Project (FANTA); 2016 (http:// www.fantaproject.org/sites/default/files/ resources/FANTA-MUAC-cutoffspregnantwomen-June2016.pdf,

16. Yu Z, HanS, ZhuJ, Sun X, Ji C, GuoX. Pre-pregnancy body mass index in relation to infant birth weight and offspring overweight/obesity: a systematic review and meta-analysis. PloS One. 2013;8(4):e61627.

17. Han Z, Lutsiv O, Mulla S, et al. Low gestational weight gain and the risk of preterm birth and low birth weight: a systematic review and meta-analyses. Acta Obstet Gynecol Scand. 2011;90(9):935-954.

18. WHO; de Benoist B, McLean E, Egli I, Cogswell M, editors. Worldwide prevalence of anaemia 1993-2005. WHO global database on anaemia. Geneva: World Health Organization (WHO); 2008 (http://apps.who.int/iris/ bitstream/10665/43894/1/9789241596657_eng.pdf

19. WHO/UNICEF Discussion paper :The extension of the 2025 Maternal, Infant and Young Child nutrition targets to 2030. https://www.who.int/nutrition/global-target-2025/discussionpaper-extension-targets-2030.pdf 
20. Soofi S, Khan GN, Sadiq K, et al. Prevalence and possible factors associated with anaemia, and vitamin B 12 and folate deficiencies in women of reproductive age in Pakistan: analysis of national-level secondary survey data. BMJ Open. 2017;7(12):e018007. Published 2017 Dec 22. doi:10.1136/bmjopen-2017-018007

21. Guideline: daily iron and folic acid supplementation in pregnant women. Geneva: World Health Organization; 2012 (http://www. who.int/nutrition/publications/micronutrients/ guidelines/daily_ifa_supp_pregnant_women/en/

22. Levels and trends in child malnutrition. UNICEF / WHO / World Bank Group Joint Child Malnutrition Estimates. 2018. Key findings of the 2018 edition. Web. < http://www.who.int/nutgrowthdb/2018-jme-brochure. pdf?ua=1>.

23. Stevens, Gretchen A, et al. "Global, Regional, and National Trends in Haemoglobin Concentration and Prevalence of Total and Severe Anaemia in Children and Pregnant and Non-Pregnant Women for 1995-2011: a Systematic Analysis of Population-Representative Data." The Lancet Global Health, vol. 1, no. 1, 2013, doi:10.1016/s2214-109x(13)70001-9.

24. Abu-Saad, Kathleen, and Drora Fraser. "Maternal Nutrition and Birth Outcomes." Epidemiologic Reviews 32.1 (2010): 5-25. 17 Mar. 2010. Web. <https://academic.oup.com/epirev/article-lookup/doi/10.1093/epirev/ mxq001>.

25. Akhtar S, Ahmed A, Randhawa MA, et al. Prevalence of vitamin A deficiency in South Asia: causes, outcomes, and possible remedies. J Health Popul Nutr. 2013;31(4):413-423. doi:10.3329/jhpn.v31i4.19975

26. Christian P, Khatry SK, Le Clerq SC, Dali SM. Effects of prenatal micronutrient supplementation on complications of labor and delivery and puerperal morbidity in rural Nepal. Int J Gynaecol Obstet. 2009;106(1):3-7.

27. Chappell LC, Cluver CA, Kingdom J, Tong S. Pre-eclampsia. Lancet. 2021 Jul 24;398(10297):341-354. doi: 10.1016/S0140-6736(20)32335-7. Epub 2021 May 27. PMID: 34051884.

28. Gernand AD, Schulze KJ, Stewart CP, West KP Jr, Christian P. Micronutrient deficiencies in pregnancy worldwide: health effects and prevention. Nat Rev Endocrinol. 2016;12(5):274289. doi:10.1038/nrendo.2016.37

29. Wessels I, Maywald M, Rink L. Zinc as a Gatekeeper of Immune Function. Nutrients. 2017;9(12):1286. Published 2017 Nov 25. doi:10.3390/nu9121286 
30. FAO, IFAD, UNICEF, WFP and WHO. 2017. The State of Food Security and Nutrition in the World 2017. Building resilience for peace and food security. Web. < http://www.fao.org/3/a-I7695e.pdf>.

31. Rich Mother, Poor Mother: The Social Determinants of Maternal Death and Disability. Fact sheet. UNFPA, Dec. 2012. Web. <https://www.unfpa.org/ sites/default/files/resourcepdf/EN-SRH\%20fact\%20sheet-Poormother. pdf>.

32. Golbasi Z., Kelleci M., Kisacik G., Cetin A. Prevalence and correlates of depression in pregnancy among Turkish women.Matern. Child Health J.2010;14:485491. [PubMed] [Google Scholar]

33. Bhutta ZA, Berkley JA, Bandsma RHJ, Kerac M, Trehan I, Briend A. Severe childhood malnutrition. Nat Rev Dis Primers. 2017;3:17067. Published 2017 Sep 21. doi:10.1038/nrdp.2017.67

34. Mahmood A, Kedia S, Wyant DK, Ahn S, Bhuyan SS. Use of mobile health applications for health-promoting behavior among individuals with chronic medical conditions. Digit Health. 2019;5:2055207619882181. Published 2019 Oct 10. doi:10.1177/2055207619882181

35. Topp CW, Østergaard SD, Søndergaard S, Bech P. The WHO-5 Well-Being Index: a systematic review of the literature. Psychother Psychosom. 2015;84(3):167-76. doi: 10.1159/000376585. Epub 2015 Mar 28. PMID: 25831962.

36. Trends in Maternal Mortality: 1990 to 2015: WHO, UNICEF, UNFPA, The World Bank and the United Nations Population Division." World Health Organization. 2015. Web. <http://apps.who.int/iris/ bitstream/10665/194254/1/9789241565141_eng.pdf?ua=1>.

37. Rao, S., Yajnik, C. S., Kanade, A., Fall, C. H. D., Margetts, B. M., Jackson, A. A., ... Desai, B. (2001). Intake of Micronutrient-Rich Foods in Rural Indian Mothers Is Associated with the Size of Their Babies at Birth: Pune Maternal Nutrition Study. The Journal of Nutrition, 131(4), 1217-1224. doi:10.1093/jn/131.4.1217

38. Murray-Kolb LE, Chen L, Chen P, Shapiro M, Caulfield L. CHERG iron report: maternal mortality, child mortality, perinatal mortality, child cognition, and estimates of prevalence of anemia due to iron deficiency. cherg.org/ publications/iron-report.pdf (accessed February 5 2014)2013.

39. Chowdhury, H.A., Ahmed, K.R., Jebunessa, F. et al. Factors associated with maternal anaemia among pregnant women in Dhaka city. BMC Women's Health 15, 77 (2015). https://doi.org/10.1186/s12905-015-0234-x

40. Folic Acid: Birth Defects COUNT. https://www.cdc.gov/ncbddd/birthdefectscount/basics.html accessed on 27.Oct.2021 
41. Persson, L. Å., Arifeen, S., Ekström, E.-C., Rasmussen, K. M., Frongillo, E. A., Yunus, M., \& MINIMat Study Team, for the. (2012). Effects of Prenatal icronutrient and Early Food Supplementation on Maternal Hemoglobin, Birth Weight, and Infant Mortality Among Children in Bangladesh. JAMA, 07(19). doi:10.1001/jama.2012.4061

42. Potdar, R. D., Sahariah, S. A., Gandhi, M., Kehoe, S. H., Brown, N., Sane, H., Fall, C. H. (2014). Improving women's diet quality preconceptionally and during gestation: effects on birth weight and prevalence of low birth weight - a randomised controlled efficacy trial in India (Mumbai Maternal Nutrition Project). The American Journal of Clinical Nutrition, 100(5), 1257-1268. doi:10.3945/ajcn.114.084921

43. American College of Obstetricians and Gynecologists. Physical activity and exercise during pregnancy and the postpartum period. Committee opinion no. 650. Obstet Gynecol 2015;126:e135-42.

44. Gülmezoglu AM, Lawrie TA, Hezelgrave N, et al. Interventions to Reduce Maternal and Newborn Morbidity and Mortality. In: Black RE, Laxminarayan R, Temmerman M, et al., editors. Reproductive, Maternal, Newborn, and Child Health: Disease Control Priorities, Third Edition (Volume 2). Washington (DC): The International Bank for Reconstruction and Development / The World Bank; 2016 Apr 5. Chapter 7. Available from: https://www.ncbi.nlm.nih.gov/books/NBK361904/ doi: 10.1596/978-1-4648-0348-2_ch7

45. National Institute of Health and Family Welfare, Government of India. National nutritional anemia prophylaxis programme. Available from:http://nihfw.nic.in/ndcnihfw/html/Programmes/NationalNutritionAnemia. htm (cited 29 July 2013). 